Jurnal Dinamika Bahari

Vol. 8 No. 2 Edisi Mei 2018

\title{
PENANGANAN BONGKAR MUAT DENGAN CRANE KAPAL DI MV. ORIENTAL JADE
}

\author{
Vega F. Andromeda ${ }^{a}$ dan Danang Wahyu Pratama ${ }^{b}$ \\ ${ }^{a}$ Dosen Program Studi Nautika PIP Semarang \\ ${ }^{\mathrm{b}}$ Taruna (NIT.50134776 N) Program Studi Nautika PIP Semarang
}

\begin{abstract}
ABSTRAK
Pelaksanaan bongkar muat dengan menggunakan crane kapal harus dilaksanakan dengan benar dan penanganan muatan yang melebihi SWL crane kapal. Dengan dasar ini penulis merumuskan masalah tentang bagaimana pelaksanaan bongkar muat dengan menggunakan crane kapal di MV. Oriental Jade dan bagaimana jika muatan melebihi SWL crane kapal. Berdasarkan hasil penelitian yang dilakukan penulis selama praktek layar di $M V$. Oriental Jade mengenai pelaksanaan bongkar muat dengan menggunakan crane kapal ditemukan adanya masalah-masalah yang meliputi persiapan crane yang terlalu lama, alat bongkar muat yang sebagian sudah tidak layak, wirerope sudah aus. Dalam pelaksanaan bongkar muat ditemukan muatan yang melebihi SWL crane akibatnya muatan tidak mampu diangkat oleh satu crane kapal sehingga dibutuhkan dua crane yang digabungkan supaya beban yang diangkat tidak terlalu berat dan muatan yang diangkat dengan HMC (Harbour Mobile Crane).
\end{abstract}

Kata kunci: bongkar muat, crane kapal, SWL crane

\section{ABSTRACT}

Implementation of loading and unloading using a ship's crane must be carried out properly and handling loads that exceed SWL crane vessels. On this basis the author formulates the problem of how the loading and unloading practices using the ship's crane in $M V$. Oriental Jade and what if the load exceeds the SWL crane of the ship. Based on the results of research conducted during the screen practice author in MV. Oriental Jade on loading and unloading activities using a ship's crane found problems encompassing crane preparations that were too long, unloading tools partly improper, wirerope worn out. In the loading and unloading operation, a load exceeding the SWL crane resulted in the inability of the load to be lifted by a crane so that two cranes were combined so that the load would not be too heavy and the load raised with HMC (Harbor Mobile Crane).

\section{Keywords: loading and unloading, ship crane, SWL crane}

\section{PENDAHULUAN}

Indonesia merupakan Negara kepulauan, maka transportasi laut merupakan sektor yang sangat penting dalam dunia perdagangan, sehingga Indonesia harus mempunyai sistem transportasi laut yang berguna dan berhasil guna (efisiensi dan efektifitas). Kebutuhan akan transportasi khususnya di bidang kelautan sangat besar, karena transportasi laut merupakan suatu alat yang dapat mengangkut penumpang atau barang dari satu tempat ke tempat yang lainnya, dengan menempuh jarak yang jauh dengan biaya yang relatif murah jika dibandingkan dengan menggunakan 
Vega F. Andromeda ${ }^{a}$ dan Danang Wahyu Pratama ${ }^{b}$

sarana transportasi darat maupun transportasi udara.

Dalam dunia perdagangan nasional maupun perdagangan internasional, pelayaran niaga sangat berperan penting untuk menunjang proses pendistribusian barang. Hampir semua barang ekspor dan impor menggunakan sarana angkutan kapal laut, walaupun diantara tempat di mana pengangkutan dilakukan terdapat fasilitasfasilitas angkutan lainnya yang berupa angkutan darat seperti truk dan kereta api. Pengangkutan barang dengan kapal laut dipilih karena jumlah barang yang diangkut akan lebih besar jika dibandingkan dengan menggunakan truk, kereta api, atau pesawat terbang dan biaya angkut juga lebih kecil jika dibandingkan dengannya.

Salah satu tujuan pengangkutan melalui kapal laut adalah mengangkut muatan melalui laut dengan cepat dan selamat sampai ke tempat tujuan. Kelancaran operasional kapal ditentukan oleh kondisi operasional kapal pada waktu melakukan kegiatan operasional bongkar muat dan pengurusan administrasi di pelabuhan asal dan pelabuhan tujuan. Untuk kelancaran kegiatan bongkar muat dari dan ke kapal, peralatan alat bongkar muat merupakan salah satu faktor yang terpenting untuk menjamin kegiatan bongkar muat di pelabuhan.

Pada tahun 2015-2016 penulis melaksanakan praktek laut di kapal MV. Oriental Jade. Kapal ini merupakan kapal jenis Container DWT (Dead Weight Tonnage) 18.000 Ton dan melayani pelayaran domestik. Selama kurun waktu 12 bulan penulis berlayar di kapal MV. Oriental Jade. Penulis menemukan beberapa masalah dalam pelaksanaan bongkar muat dengan menggunakan crane kapal di MV. Oriental Jade. Beberapa diantaranya adalah pelaksanaan bongkar muat yang melebihi SWL crane kapal.

Berdasarkan kenyataan di atas saat kapal melakukan aktifitas bongkar muat barang dari kapal ke dermaga dan dari dermaga ke kapal atau juga dari kapal ke kapal diperlukan tenaga ahli dan tenaga kerja atau buruh bongkar muat yang profesional dan peralatan bongkar muat yang baik pula kondisinya untuk kelancaran bongkar muat tersebut.

Pada saat pelaksanaan bongkar muat dengan menggunakan crane kapal masih terdapat kendala yang membuat crane berjalan lamban dan pelaksanaan bongkar muat tidak dapat berjalan sebagaimana mestinya. Tentunya hal ini membuat pelaksanaan bongkar muat tidak sesuai dengan prinsip pemuatan. Semua akan berjalan lancar jika ada kerja sama yang baik antara pemilik muatan, pengangkut dan buruh.

Atas munculnya permasalahan di atas penulis ingin mengangkat fenomena tersebut dalam penelitian yang berjudul "Pelaksanaan Bongkar Muat Dengan Menggunakan Crane Kapal Di MV. Oriental Jade". Hal ini bertujuan untuk mencari pemecahan masalah dengan cara penanggulangan yang tepat dalam mengatasi permasalahan pada saat pelaksanaan bongkar muat, sehingga di kemudian hari permasalahan yang sama tidak akan terulang lagi serta kegiatan operasional dapat berjalan dengan lancar.

Berdasarkan judul dan latar belakang yang telah diuraikan penulis, maka penulis merumuskan masalah-masalah yang akan dibahas dalam penelitian ini adalah :

1. Bagaimana pelaksanaan bongkar muat dengan menggunakan crane kapal di MV. Oriental Jade?

2. Bagaimana jika muatan melebihi kapasitas dari SWL crane kapal di MV. Oriental Jade?

Berdasarkan rumusan masalah di atas, maka tujuan penulisan ini, yaitu:

1. Untuk mengetahui bagaimana pelaksanaan bongkar muat dengan menggunakan crane kapal di MV. Oriental Jade. 
2. Untuk mengetahui cara menangani muatan yang melebihi SWL crane kapal.

\section{KAJIAN PUSTAKA}

Menurut penelitian yang dilakukan Asisten Wakil Rektor senior akademik bidang operasional pendidikan dan pengendalian mutu (2004), "Pelaksanaan yang berarti telah memiliki organisasi dan prosedur pelaksanaan pada tingkat universitas, fakultas, jurusan atau bagian dan program studi, termasuk didalamnya adalah sumber daya manusia untuk melaksanakan". Menurut Komarudin (2004:3), "Pelaksanaan adalah sistim pembentukan jaringan yang dengan istimewa diciptakan untuk membantu pimpinan dalam pengawasan biaya yang dibutuhkan untuk program, jumlah keperluan, dan waktu". Berdasarkan definisi tersebut, penulis menyimpulkan bahwa pelaksanaan adalah perbuatan melaksanakan suatu pekerjaan atau tindakan yang sudah direncanakan atau keputusan untuk mencapai tujuan yang diinginkan.

Menurut Soegiyanto dan Martopo (2004:30) "Proses bongkar muat adalah kegiatan mengangkat, mengangkut serta memindahkan muatan dari kapal ke dermaga pelabuhan atau sebaliknya". Sedangkan proses bongkar muat barang umum di pelabuhan meliputi stevedoring (pekerjaan bongkar muat kapal), cargodoring (operasi transfer tambatan), dan receiving / delivery (penerima / penyerahan) yang masing-masing dijelaskan di bawah ini:

a. Stevedoring (pekerjaan bongkar muat kapal)

Menurut Soegiyanto dan Martopo (2004:30) "stevedoring (pekerjaan bongkar muat kapal) adalah jasa pelayanan membongkar dari/kapal, dermaga, tongkang, truk atau muat dari/ke dermaga, tongkang, truk ke/dalam palka dengan menggunakan derek kapal atau yang lain". Petugas stevedoring (pekerjaan bongkar muat kapal) dalam mengerjakan bongkar muat kapal, selain foreman (pembantu stevedor) juga ada beberapa petugas lain yang membantu stevedore dalam melaksanakan kegiatan bongkar muat (pemborong bongkar muat kapal), yaitu:

1. Cargo surveyor perusahaan PBM;

2. Petugas barang berbahaya;

3. Administrasi;

4. Cargodoring (operasi transfer tambatan)

Menurut Soegiyanto dan Martopo (2004:32) "cargodoring (operasi transfer tambatan) adalah pekerjaan mengeluarkan barang atau muatan dari sling di lambung kapal di atas dermaga, mengangkut dan menyusun muatan di dalam gudang atau lapangan penumpukan dan sebaliknya".

Dalam pelaksanaan produktifitas cargodoring dipengaruhi oleh tiga variabel, yakni jarak tempuh, kecepatan kendaraan, dan waktu tidak aktif :

1) jarak yang ditempuh

2) kecepatan kendaraan

3) waktu tidak aktif (immobilisasi)

b. Receiving atau Delivery (penerima/ penyerahan)

Adalah pekerjaan mengambil barang atau muatan dari tempat penumpukan atau gudang hingga menyusunnya di atas kendaraan pengangkut keluar pelabuhan atau sebaliknya. Kegiatan receiving (penerima) ini pada dasarnya ada dua macam, yaitu :

1) Pola muatan angkutan langsung adalah pembongkaran atau pemuatan dari kendaraan darat langsung dari dan ke kapal.

2) Pola muatan angkutan tidak langsung adalah penyerahan atau penerimaan barang/peti kemas setelah melewati gudang.

Terlambatnya operasi delivery (penyerahan) dapat terjadi disebabkan : 
Vega F. Andromeda ${ }^{a}$ dan Danang Wahyu Pratama ${ }^{b}$

1) Cuaca buruk / hujan waktu bongkar / muatan dari kapal.

2) Terlambatnya angkutan darat, atau terlambatnya dokumen.

3) Terlambatnya informasi atau alur dari barang.

4) Perubahan alur dari loading point (nilai pemuatan).

Menurut Soegiyanto dan Martopo (2004:7), "stowage atau Penataan muatan merupakan suatu istilah dalam kecakapan pelaut, yaitu suatu pengetahuan tentang memuat dan membongkar muatan dari dan ke atas kapal sedemikian rupa agar terwujud 5 prinsip pemuatan yang baik". Untuk itu para perwira kapal dituntut untuk memiliki pengetahuan yang memadai baik secara teori maupun praktek tentang jenis-jenis muatan, perencanaan pemuatan, sifat dan kualitas barang yang akan dimuat, perawatan muatan, penggunaan alat-alat pemuatan, dan ketentuan-ketentuan lain yang menyangkut masalah keselamatan kapal dan muatan. Adapun 5 prinsip pemuatan yang baik adalah :

a. Melindungi awak kapal dan buruh

(Safety of crew and longshoreman)

Melindungi awak kapal dan buruh adalah suatu upaya agar mereka selamat dalam melaksanakan kegiatan. Untuk itu perlu diperhatikan hal-hal sebagai berikut :

1) Penggunaan alat-alat keselamatan kerja secara benar, misalnya sepatu keselamatan, helm, kaos tangan, pakaian kerja;

2) Memasang papan-papan peringatan;

3) Memperhatikan komando dari kepala kerja;

4) Tidak membiarkan buruh lalu lalang di daerah kerja;

5) Tidak membiarkan muatan terlalu lama menggantung lama di tali muat;
6) Memeriksa peralatan bongkar muat sebelum digunakan sehingga dalam keadaan baik;

7) Tangga akomodasi (gang way) diberi jaring;

8) Memberi penerangan secara baik dan cukup saat bekerja pada malam hari;

9) Bekerja secara tertib dan teratur mengikuti perintah;

10) Jika ada muatan di deck, dibuatkan jalan lalu lalang orang secara bebas dan aman;

11) Semua muatan yang dapat bergerak di-lashing dengan kuat;

12) Muatan di deck memiliki ketinggian yang tidak mengganggu penglihatan saat bernavigasi;

13) Mengadakan tindakan berjagajaga secara baik;

14) Muatan berbahaya harus dimuat sesuai dengan SOLAS.

b. Melindungi kapal (to protect the ship)

Melindungi kapal adalah suatu upaya agar kapal tetap selamat selama kegiatan muat bongkar maupun dalam pelayaran, misalnya menjaga stabilitas kapal, jangan memuat melebihi deck load capacity, memperhatikan SWL (Safety Working Load) peralatan muat bongkar.

c. Melindungi muatan (to protect the cargo)

Dalam peraturan perundangundangan internasional dinyatakan bahwa perusahaan atau pihak kapal bertanggung jawab atas keselamatan dan keutuhan muatan sejak muatan itu dimuat sampai muatan itu dibongkar. Oleh karena itu pada waktu memuat, membongkar, dan selama dalam pelayaran, muatan harus ditangani secara baik. Pada umumnya kerusakan muatan disebabkan oleh :

1) Pengaruh dari muatan lain yang berada dalam satu ruang palka; 
Jurnal Dinamika Bahari

Vol. 8 No. 2 Edisi Mei 2018

2) Pengaruh air, misalnya terjadi kebocoran, keringat kapal, keringat muatan, dan kelembaban udara dalam ruang palka;

3) Gesekan antar muatan dengan badan kapal;

4) Penanggasan (panas) yang ditimbulkan oleh muatan itu sendiri;

5) Pencurian (pilferage);

6) Penanganan muatan yang tidak baik.

d. Melakukan muat bongkar secara cepat dan sistematis (rapit and systematic loading and discharging).

Agar pelaksanaan pemuatan dan pembongkaran dapat dilakukan secara cepat dan sistematis, maka sebelum kapal tiba di pelabuhan pertama di suatu negara, harus sudah tersedia rencana pemuatan dan pembongkaran (stowage plan). Meskipun telah direncanakan secara baik dan dilaksanakan dengan baik pula, namun masih sering terjadi adanya kekeliruan-kekeliruan seperti timbulnya long hatch, over stowage, over carriage ini harus dihindarkan.

e. Penggunaan ruang muat semaksimal mungkin.

Dalam melakukan pemuatan harus diusahakan agar semua ruang muat dapat terisi penuh oleh muatan atau kapal dapat memuat sampai sarat maksimum, sehingga dapat diperoleh uang tambang yang maksimal. Namun demikian, karena bentuk paking muatan tertentu, sering muatan tidak dapat memenuhi ruang muat, kemungkinan lain adalah cara pemadatan yang kurang baik, sehingga banyak ruang muat yang tidak terisi oleh muatan. Ruang muatan yang tidak terisi muatan disebut broken stowage. Dalam prinsip pemuatan, broken stowage harus diusahakan sekecil mungkin dengan cara :

1) Menggunakan/memuat muatan pengisi (filler cargo);
2) Melaksananakan perencanaan yang baik;

3) Pengawasan pada waktu pelaksanaan pemuatan;

4) Penggunaan terap muatan (dunnage) secara efisien;

5) Penggunaan ruang palka disesuaikan dengan bentuk muatan.

Menurut Martopo dan Soegiyanto (2004:38-71) "Crane kapal adalah alat bongkar muat yang dirancang khusus di atas kapal yang digunakan sebagai alat pengangkat". Crane bekerja dengan mengangkat material yang akan dipindahkan, memindahkan secara horizontal, kemudian menurunkan material di tempat yang diinginkan. Alat ini memiliki bentuk dan kemampuan angkat yang besar dan mampu berputar hingga 360 derajat dan jangkauan hingga puluhan meter. Crane biasanya digunakan untuk mengambil muatan dari dermaga ke kapal. Crane terdiri dari beberapa bagian antara lain :

1) Tiang crane yang dilengkapi dengan rel crane (gigi roda yang berputar) agar bisa bergerak ke kiri maupun ke kanan 360 derajat.

2) Boom yaitu batang pemuat yang dilengkapi dengan hydraulic untuk mengangkat ke atas dan ke bawah.

3) Crane house atau rumah crane adalah tempat untuk mengontrol dari pada crane tersebut di mana operator sebagai pengoperasinnya.

4) Kerek muat atau cargo block adalah jalur wire untuk bergerak yang berada di ujung batang pemuat.

5) Wire drum adalah tempat untuk melilitnya wire.

6) Wire adalah kawat sebagai penerus dari gerakan yang dihasilkan oleh winch.

7) Motor penggerak atau winch adalah penggerak utama dari 
Vega F. Andromeda dan Danang Wahyu Pratama ${ }^{\mathrm{b}}$

setiap gerakan yang ada, seperti menaikturunkan spreader.

8) Spreader adalah alat bantu untuk mengangkat equipment atau obyek/material lain.

Untuk kapal cargo modern sering digunakan deck crane (geladak kran) sebagai alat bongkar muat dan untuk kapal-kapal khusus menggunakan alat muat bongkar yang sesuai dengan jenis barang yang diangkut. Pada batang pemuat tertera berat beban maka yang dapat diangkut dengan aman oleh batang pemuat tersebut. Panjang batang pemuat sedemikian rupa, sehingga dapat mengambil muatan di samping lambung kapal. Panjang batang pemuat sedemikian rupa sehingga kalau batang tersebut diturunkan sampai sudut $25^{0}$ dengan bidang datar, maka tali muat dan kait muat harus bisa mencapai 2,5 meter di lambung kapal.

Panjang batang pemuat harus mencapai pojok terjauh dan tali muatnya harus tersisa 4 s.d 6 gulungan di winch roller (gulungan mesin derek). Pemasangan batang pemuat dilakukan sedemikian rupa, sehingga dapat digerakkan naik turun, mendatar kekiri dan kekanan. Gerakan ini disebabkan oleh adanya baut pada ujung bawah batang pemuat tersebut. Di beberapa negara penggunaan alat-alat ini didasarkan atas sertifikat yang dikeluarkan oleh Surveyor dari Internasional Cargo Gear Bearau $(I C C B)$ atau (biro klasifikasi tentang perawatan peralatan bongkar muat), yang menyatakan bahwa setelah memeriksa dan melakukan tes, maka alat-alat pemuatan tersebut telah memenuhi syarat keamanannya. "Pada kapal pelayaran samudera maka setiap tiang pada umumnya paling sedikit 2 boom (batang pemuat)" (Istopo, 1999:17).

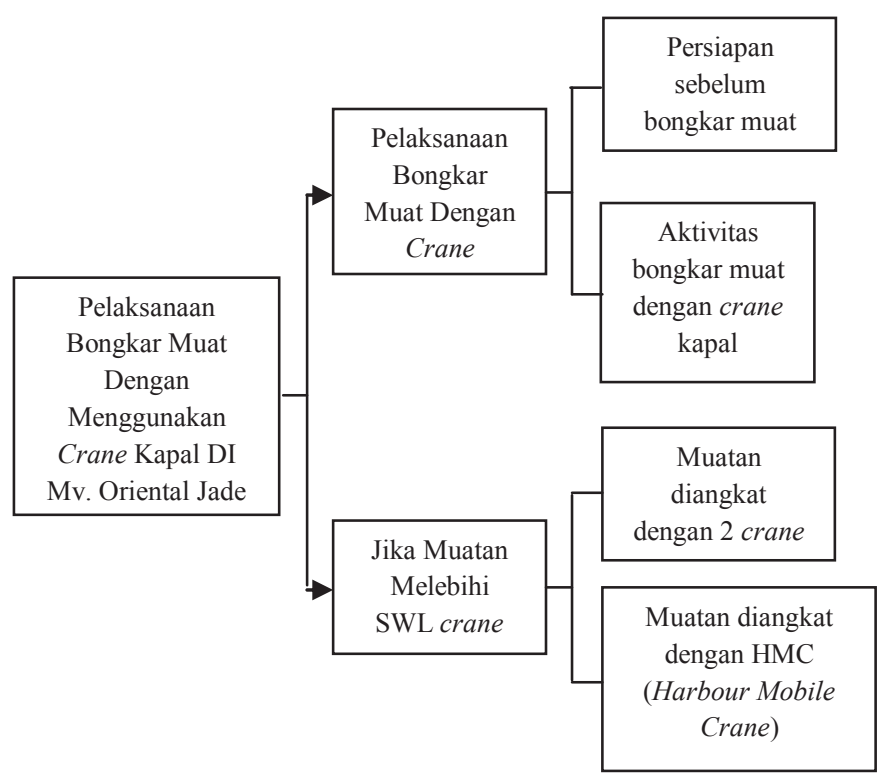

Gambar 1. Kerangka Berpikir

\section{METODOLOGI}

Kata metodologi berasal dari penggabungan dua kata yang berasal dari Yunani, yaitu metodos dan logos. Metodos berarti melalui dan logos berarti ilmu pengetahuan. Metode merupakan suatu kerangka kerja untuk melakukan suatu tindakan atau suatu kerangka berfikir untuk menyusun suatu gagasan yang beraturan, berarah dan berkonteks dengan maksud dan tujuan.

Metode penelitian yang digunakan oleh Penulis adalah metodologi penelitian deskriptif kualitatif untuk menggambarkan dan menguraikan objek yang diteliti serta kaidah-kaidah yang diambil dari teori-teori yang berhubungan dengan topik yang dibahas, selain itu juga menggunakan pendekatan di lapangan yang telah dilaksanakan selama praktek laut dengan cara wawancara dan pengamatan. Adapun hal-hal yang diamati adalah tentang pelaksanaan bongkar muat dengan menggunakan crane kapal, yang kegiatannya dilaksanakan di kapal MV. Oriental Jade. Dengan adanya penelitian ini diharapkan hubungan antara pokok 
permasalahan dengan metode pemecahannya akan lebih jelas, sehingga selanjutnya dapat dicari usaha dan upaya untuk menanggulangi masalah tersebut.

\section{Metode deskriptif}

Metode penelitian deskriptif adalah metode penelitian yang dilakukan untuk mengetahui nilai variabel mandiri atau lebih (independen) tanpa membuat perbandingan atau menggabungkan antara variabel satu dengan yang lain. (Sugiyono, 2012:35). Pada bagian ini peneliti akan mendeskripsikan tentang pelaksanaan bongkar muat dengan menggunakan crane kapal.

2. Metode kualitatif

Metode penelitian kualitatif adalah metode penelitian yang berlandaskan pada filsafat post positivisme, digunakan untuk meneliti pada kondisi objek yang alamiah, (sebagai lawannya adalah eksperimen) di mana peneliti adalah sebagai instrumen kunci, teknik pengumpulan data dilakukan secara triangulasi (gabungan), analisis data bersifat induktif/kualitatif, dan hasil penelitian lebih menekankan makna generalisasi. (Sugiyono, 2012:13).

Menurut Sukardi dalam bukunya Metodologi Penelitian Pendidikan (2003:53), menerangkan bahwa yang dimaksud dengan tempat penelitian yaitu tempat di mana proses studi yang digunakan untuk memperoleh pemecahan masalah penelitian berlangsung. Penelitian ini dilakukan selama penulis melaksanakan praktek laut di atas kapal MV. Oriental Jade armada milik PT. Salam Pacific Indonesia Lines berbendera Indonesia dengan homeport Jakarta yang beralamat J1. Kali Anak No. 51 F, Surabaya. Pada saat penulis melaksanakan praktek laut dari bulan September 2015 sampai dengan bulan September 2016.

Data adalah suatu informasi yang digunakan dalam suatu penelitian agar dapat dilakukan pembahasan. Data yang diperoleh dengan analisis. Berdasarkan cara memperolehnya, data yang diperoleh selama penelitian sebagai pendukung tersusunnya penulisan penelitian ini diantaranya :

\section{Data primer}

Data Primer adalah data yang berasal dari sumber asli atau pertama. Data ini tidak tersedia dalam bentuk terkompilasi ataupun dalam bentuk file-file. Data ini harus dicari melalui narasumber atau dalam istilah teknisnya responden, yaitu orang yang kita jadikan objek penelitian atau orang yang kita jadikan sebagai sarana mendapatkan informasi ataupun data. Penulis memperoleh data melalui wawancara dengan Mualim I MV. Oriental Jade yang berhubungan dengan pelaksanaan bongkar muat dengan menggunakan crane kapal.

\section{Data sekunder}

Data sekunder merupakan data yang sudah tersedia sehingga kita tinggal mencari dan mengumpulkan. Data sekunder dapat diperoleh dengan mudah dan cepat. Karena sudah tersedia, misalnya di perpustakaan, organisasiorganisasi perdagangan, dan kantorkantor pemerintah.

Beberapa pertimbangan dalam mencari data sekunder:

a. Jenis data sesuai dengan tujuan penelitian yang sudah ditentukan.

b. Data sekunder yang dibutuhkan bukan menekankan pada jumlah tetapi pada kualitas, oleh karena itu harus selektif dan hati-hati.

c. Data sekunder biasanya digunakan sebagai pendukung data primer, oleh karena itu keduanya saling digunakan sebagai sumber informasi untuk menyelesaikan masalah penelitian.

Data menjadi sangat penting bagi diperolehnya jawaban yang benar atas masalah yang diteliti. Untuk memperoleh jawaban yang benar, diperlukan data yang benar, dan untuk 
Vega F. Andromeda ${ }^{a}$ dan Danang Wahyu Pratama ${ }^{b}$

memperoleh data yang benar diperlukan metode pengumpulan yang benar.

Di dalam penelitian ini penulis menggunakan beberapa metode pengumpulan data antara lain :

1. Metode observasi

Menurut Nazir (2005:175), pengumpulan data dengan observasi langsung atau dengan pengamatan langsung adalah cara pengambilan data dengan menggunakan mata tanpa ada pertolongan alat standar lain untuk keperluan tersebut. Dalam hal ini penulis melaksanakan pengamatan secara langsung saat melaksanakan praktek laut di MV. Oriental Jade, khususnya saat pelaksanaan bongkar muat dengan menggunakan crane kapal.

2. Metode Wawancara

$$
\text { Menurut Nazir (2005:193), }
$$
wawancara adalah proses memperoleh keterangan untuk tujuan penelitian dengan cara tanya jawab, sambil bertatap muka antara pewawancara dengan atau responden dengan menggunakan alat yang dinamakan interview guide. Wawancara sebagai metode pengumpul data, adanya komunikasi langsung antara penulis dengan sasaran penelitian yaitu Mualim I di MV. Oriental Jade sebagai narasumber.

3. Metode Kepustakaan

Metode kepustakaan digunakan dengan maksud untuk mendapatkan atau mengumpulkan data dengan jalan mempelajari buku-buku yang berkaitan dengan pokok masalah yang diteliti, juga sebagai pelengkap data apabila terdapat kesulitan dalam pemecahan-pemecahan masalah dalam penelitian.

4. Dokumentasi

Menurut Hadari Nawawi dalam bukunya Metode Penelitian Bidang
Sosial (2004:133), teknik dokumentasi yaitu cara pengumpulan data melalui peninggalan tertulis, terutama berupa arsip-arsip dan termasuk juga buku-buku tentang pendapat, teori, dalil atau hukumhukum dan lain-lain yang berhubungan dengan masalah penyelidikan.

Menurut Supardi (2003:7), dalam proses penelitian, pengetahuan yang diperoleh dari kepustakaan yang relevan dengan topik sangat penting dan perlu, karena dapat memberikan latar belakang informasi, memberikan arahan terhadap pendekatan teoritis yang sesuai, menunjukkan bidang topik yang harus dimasukkan ke dalam atau dikeluarkan dari fokus penelitian, dan menghindari terjadinya duplikasi penelitian yang tak perlu. Kepustakaan yang paling penting adalah yang berisi hasil, penelitian yang pernah dilakukan oleh penelitian orang lain.

\section{DISKUSI}

Berdasarkan analisa penelitian di atas kapal, penulis menemukan beberapa permasalahan yang berhubungan dengan perawatan alat bongkar muat khususnya derrick boom (batang pemuat derek) yaitu tentang:

1. Pelaksanaan bongkar muat dengan crane kapal

Dalam penelitian ini, pelaksanaan bongkar muat dengan menggunakan crane kapal dapat ditemukan pada hal yang terkait dengan persiapan, pelaksanaan, dan perawatan crane. Persiapan sebelum pelaksanaan bongkar muat dengan crane, pelaksanaan bongkar muat dengan crane serta perawatan crane diantaranya meliputi:

a. Persiapan sebelum pelaksanaan bongkar muat 
1) Persiapan crane yang akan digunakan untuk kegiatan bongkar muat

2) Persiapan alat bongkar muat

3) Persiapan Tenaga Kerja Bongkar Muat

b. Aktivitas pembongkaran dan pemuatan dengan menggunakan crane kapal :

1) Aktivitas pembongkaran dengan menggunakan crane kapal

2) Aktivitas pemuatan dengan menggunakan crane kapal

2. Muatan yang melebihi SWL crane kapal.

Safe Working Load (Beban Kerja Aman) adalah beban maksimum yang ditanggung oleh sling pada saat benda diangkat secara tidak langsung karena adanya pengikatan sling pada benda. Sling tidak digunakan untuk mengangkat beban yang melebihi SWL yang tertera pada label sebuah sling. Muatan yang melebihi SWL adalah muatan yang bobotnya melebihi kapasitas beban kerja aman. Jumlah crane di MV. Oriental Jade berjumlah 3 crane, dengan masingmasing kapasitas SWL 30 ton, 30 ton, dan 25 ton. Muatan yang melebihi SWL crane tidak bisa diangkat jika hanya mengandalkan satu crane dengan maksimal SWL 30 ton. Maka dari itu cara menangani muatan yang melebihi SWL crane adalah dengan cara berikut:

a. Muatan diangkat dengan 2 crane

Ketika menemukan muatan yang melebihi SWL crane maka cara menanganinya adalah dengan cara menggunakan 2 crane yang digabungkan untuk mengangkat beban yang melebihi SWL. Dengan menggabungkan 2 crane untuk mengangkat, maka tanggungan beban pada masing-masing crane menjadi lebih ringan. b. Muatan diangkat dengan HMC (Harbour Mobile Crane) HMC (Harbour Mobile Crane) alat bongkar muat di pelabuhan /crane yang dapat berpindah pindah tempat serta memiliki sifat yg flexible sehingga bisa digunakan untuk bongkar/muat peti kemas dengan kapasitas angkat/SWL (Safety Weight Load) sampai dgn 100 ton. Untuk mengangkat muatan yang melebihi SWL crane dapat dengan mudah di angkat.

Pelaksanaan bongkar muat dengan menggunakan crane kapal di MV. Oriental Jade dilaksanakan oleh pihak kapal yang dioperatori oleh pihak darat dengan cara membongkar muatan untuk diturunkan ke darat dengan menggunakan crane kapal dan mengangkat muatan untuk dinaikkan ke masing-masing palka sesuai dengan stowage plan yang dibuat oleh Mualim I menggunakan crane kapal. Berdasarkan analisa penelitian di atas kapal, penulis menemukan beberapa permasalahan yang berhubungan dengan pelaksanaan bongkar muat dengan menggunakan crane kapal yaitu tentang:

1. Pelaksanaan bongkar muat dengan menggunakan crane kapal.

Berdasarkan dengan apa yang telah penulis amati di atas kapal, penulis akan menjelaskan tentang bagaimana pelaksanaan bongkar muat dengan menggunakan crane kapal:

a. Persiapan sebelum bongkar muat

Sesaat setelah kapal sandar di pelabuhan bongkar muat Sorong, cadet dan crew membuka lashing muatan. Sebelumnya menanyakan kepada Mualim I palka mana yang akan dibongkar atau dimuat, agar pelaksanaan melepas lashing terlaksana dengan benar. Setelah lashing muatan telah selesai dibuka, crew akan mempersiapkan 
Vega F. Andromeda ${ }^{a}$ dan Danang Wahyu Pratama ${ }^{b}$

crane untuk kegiatan bongkar muat. Adapun kegiatan tersebut adalah :

1) Persiapan crane yang akan digunakan untuk kegiatan bongkar muat.

Dari hasil wawancara dengan narasumber yaitu Mualim I tentang bagaimana cara menghidupkan crane yang akan digunakan untuk kegiatan bongkar, dikatakan bahwa :

"Mualim I akan menghubungi Engine Control Room untuk meminta menghidupkan crane untuk digunakan dalam kegiatan bongkar muat yang membutuhkan daya lebih besar maka untuk menunjang hal tersebut dibutuhkan peran Departemen Mesin”

Dalam pelaksanaan persiapan crane, semua bagian crane harus dicek sebelum digunakan dalam kegiatan bongkar muat, oleh karena itu Mualim I sebagai perwira yang bertanggung jawab terhadap muatan perlu mengadakan pengecekan dan pendataan tentang alat-alat tersebut. Adapun bagian crane yang harus dicek diantaranya :

a) Cargo Block

Cargo block digunakan untuk mengaitkan sling wire yang akan digunakan untuk mengangkat muatan harus dicek dengan benar. Guna memastikan kelayakan cargo block maka bosun akan mengecek cargo block tersebut kemudian melaporkan kepada Mualim I bahwa cargo block siap untuk digunakan.

b) Wire drum
Drum ini berbentuk lingkaran dan menjadi wadah bagi wirerope. Di drum ini, wirerope tergulung rapi dan dengan bentuk drum yang melingkar memudahkan wirerope untuk keluar masuk ketika dioperasikan. Putaran wirerope di dalam wire drum harus dicek dan diperhatikan agar tidak terbelit di dalam wire drum.

c) Wirerope

Wirerope ini terdapat di wiredrum. Panjangnya 200 meter dalam 1 gulungan. Wire ini harus selalu diberikan grease agar tidak berkarat. Mengecek wirerope dapat dilakukan dengan 2 cara yaitu:

i) Secara visual

Lihat fisik dari wirerope sling apakah fisik berubah mengecil, bengkok atau ada kerusakan lain misalnya ada wire yang putus (dalam ukuran panjang 1 meter terdapat wire 6 putus wirerope tersebut sudah tidak layak pakai). Metode ini dilakukan pada setiap saat waktu sling digunakan.

ii) Menggunakan alat ukur

Ukur dimensi wirerope sling, jika dimensi menyusut $10 \quad \%$ dari ukuran aslinya maka wirerope tersebut sudah tidak layak pakai.

d) Motor

Motor listrik dengan memanfaatkan medan 
Jurnal Dinamika Bahari

Vol. 8 No. 2 Edisi Mei 2018

$$
\begin{array}{lr}
\text { magnet } & \text { untuk } \\
\text { menciptakan } & \text { gerakan. } \\
\text { Gerakan } & \text { tersebut } \\
\text { menggerakkan } & \text { gear } \\
\text { kemudian diteruskan ke } \\
\text { drum. }
\end{array}
$$

2) Persiapan alat bongkar muat

Persiapan alat bongkar muat merupakan hal yang penting guna menunjang kegiatan bongkar muat dengan menggunakan crane kapal dapat berjalan dengan baik dan tanpa kendala. Karena persiapan ini berkaitan dengan persiapan crane. Hal ini juga diungkapkan oleh Narasumber yaitu Mualim I tentang persiapan alat bongkar muat, dikatakan bahwa :

"Persiapan alat bongkar muat merupakan hal yang penting yang berkaitan dengan kegiatan bongkar muat dengan crane kapal agar berjalan dengan baik dan tanpa kendala"

Alat bongkar muat yang harus dipersiapkan adalah sebagai berikut:

a) Spreader

Spreader adalah alat bantu untuk mengangkat kontainer. Spreader berfungsi untuk menyebarkan beban dari 1 lifting point dari crane atau lifting equipment lainnya menjadi beberapa titik. Spreader dapat diatur panjang pendeknya sesuai panjang kontainer.

b) Sling wire

Sling wire nantinya akan dikaitkan dengan cargo block, dan dipasangi cargo hook. Sling wire ini mempunyai jenis dan diameter berbeda-beda tergantung dari muatan yang akan diangkat. Jika muatan yang diangkat semakin berat maka jenis dan diameter sling juga akan semakin bertambah. Sling yang digunakan di atas kapal mempunyai beban maksimum hingga 35 ton. Jika beban melebihi 35 ton, maka sling wire akan putus karena tidak kuat menahan.

c) Cargo hook

Cargo hook befungsi untuk mengaitkan pada kontainer. Petunjuk penggunaan cargo hook:

i) Lakukan pemeriksaan berkala apakah ada keretakan, cuil, bengkok dan faktor lain yang dapat menyebabkan kerusakan pada hook.

ii) Lakukan pemeriksaan oleh crew yang sudah berpengalaman misalnya bosun.

iii) Untuk penggunaan hook bekas harus dilakukan inspeksi dengan magnetic particle dan Dye Penetrant oleh orang yang berpengalaman terlebih dahulu secara berkala.

iv) Jangan menggunakan hook yang sudah mengalami pemegaran leher maksimal $5 \%$ dari bentuk awal.

v) Jangan menggunakan hook yang bengkok dan jangan berusaha meluruskan hook yang telah bengkok untuk dipakai lagi. 
Vega F. Andromeda ${ }^{a}$ dan Danang Wahyu Pratama ${ }^{b}$

vi) Berat beban tidak boleh melebihi working load hook.

vii) Dilarang memperbaiki, meluruskan, mengerjakan ulang ataupun membentuk ulang hook dengan cara dipanaskan, dibakar, dilelehkan ataupun di press.

viii) Jangan menggunakan hook dengan posisi terhalang benda atau balok.

ix) Jangan menggunakan hook dengan posisi dimiringkan.

3) Persiapan Tenaga Buruh Bongkar Muat (TKBM)

Tenaga Buruh Bongkar Muat (TKBM) biasanya 1-2 regu yang terdiri dari 8-12 orang setiap regunya. Jam kerja TKBM diatur dalam shift jam kerja selama 8 jam termasuk istirahat 1 jam kecuali hari jum'at siang istirahat 2 jam, untuk kegiatan bongkar muat dengan penggantian tenaga kerja bongkar muat pada setiap gilir kerja. Mereka akan dibagi tugas sesuai tugasnya masingmasing. Setiap orang mempunyai tugas kerja tersendiri, diantaranya sebagai:
a. Operator crane
b. Signalman
c. Buruh bongkar
d. Buruh muat

b. Aktivitas bongkar muat dengan crane kapal

1) Aktivitas pembongkaran dengan menggunakan crane kapal:
a) Perlengkapan dokumen dan komunikasi:

i) Foreman yang ditunjuk perusahaan akan naik ke kapal ketika kapal telah selesai sandar di dermaga. Foreman akan menemui Mualim I selaku perwira penanggung jawab muatan utntuk menyerahkan bayplan kemudian memastikan kapal siap untuk melaksanakan kegiatan bongkar muat sesuai bayplan.

ii) Sebelum melaksanakan aktivitas bongkar muat, terlebih dahulu Mualim I meminta kepada Engine Control Room untuk standby crane untuk digunakan kegiatan bongkar muat.

b) Penggunaan

Alat Bongkar Muat:

i) TKBM yang sudah berada di atas kapal akan membuka lashing peti kemas sesuai arahan dari foreman. Tidak semua lashing dibuka di pelabuhan tersebut karena muatan juga dibongkar di pelabuhan yang lain.

ii) Spreader beams/wire ropes/steel bars (lifting equipment) harus dipasang dengan benar agar ketika peti kemas diangkat dengan crane kapal tidak jatuh atau mengalami kerusakan.

iii)Masing-masing sudut peti kemas tersebut akan dikaitkan oleh 
TKBM dengan benar guna menghindari terlepasnya kaitan ketika diangkat dengan crane kapal.

iv)Operator crane kapal dan foreman akan berkomunikasi dengan walkie talkie ketika pelaksanaan bongkar muat. Operator crane akan membongkar sesuai daftar peti kemas.

v) Foreman/Supervisor akan memeriksa apakah peti kemas yang dibongkar tersebut benar, kemudian foreman memberikan perintah kepada operator crane untuk mengangkat peti kemas.

vi) TKBM akan membantu operator crane selama pelaksanaan bongkar, sebagian TKBM memasang lifting equipment, kemudian salah satu TKBM memberikan hand signal untuk memberi aba-aba kepada operator crane.

vii) Setelah peti kemas berhasil diangkat menuju truck trailer/on chassis, kemudian TKBM di darat melepas lifting equipment yang terpasang pada masing-masing sudut.
2) Aktivitas pemuatan dengan crane kapal

a) Posisikan dengan benar spreader beams/wire ropes/steel bars (lifting equipment) di atas peti kemas. TKBM akan memasang spreader beams/wire ropes/steel bars (lifting equipment) pada masing-masing sudut peti kemas. Signalman akan memberi aba-aba ketika pemasangan telah siap.

b) Angkat peti kemas dimaksud sesuai dengan daftar peti kemas muat ke kapal tersebut. Jika sudah siap maka signalman akan memberi aba-aba kepada operator crane untuk mengangkat peti kemas tersebut ke atas kapal sesuai bay plan.

c) TKBM (Signalman) memandu operator crane kapal selama pemuatan peti kemas di bay kapal. Selama kegiatan pemuatan, signalman tetap memandu operator crane kapal hingga peti kemas benar-benar dimuat di bay kapal. Operator crane kapal meletakkan peti kemas sesuai dengan bay yang ditentukan.

d) Sebelum peti kemas diletakkan di bay kapal, TKBM terlebih daluhu memasang cones agar muatan tidak bergeser ketika kapal miring atau terkena cuaca buruk. Cones juga dipasang pada masing-masing sudut 
Vega F. Andromeda ${ }^{a}$ dan Danang Wahyu Pratama ${ }^{b}$

diantara dua peti kemas yang disusun tegak.

e) Jika in hold telah penuh maka operator crane akan menutup palka kemudian melanjutkan pemuatan on deck.

f) Pelaksanaan pemuatan telah selesai, kemudian TKBM melakukan pelashingan peti kemas pada setiap tier dengan lashing silang.

Kegiatan tersebut dilakukan ketika sedang melaksanakan bongkar muat di Pelabuhan Sorong, dikarenakan di Pelabuhan Sorong tidak ada alat bongkar muat HMC (Harbour Mobile Crane) maupun $\mathrm{CC}$ (Container Gantry Crane). Kegiatan bongkar muat hanya dengan crane kapal ataupun dengan menyewa base crane untuk kapal-kapal yang tidak dilengkapi dengan crane kapal. Pada saat melakukan kegiatan bongkar muat dengan menggunakan crane, penulis menemukan hambatan yang mengganggu kelancaran pelaksanaan bongkar muat.

2. Jika muatan melebihi SWL crane kapal

Pelaksanaan bongkar muat dengan menggunakan crane kapal mempunyai kendala-kendala. Muatan yang melebihi SWL tidak bisa dipaksa untuk diangkat, karena beban melebihi kapasitas. Jika tetap dipaksakan maka yang terjadi adalah rusaknya cargo block dan wire akan putus. Dari hasil wawancara dengan narasumber yaitu Mualim I tentang muatan yang melebihi SWL crane dikatakan bahwa:

"muatan yang melebihi SWL crane tidak bisa dipaksa untuk diangkat, jika dipaksa akan mengakibatkan kerusakan yang fatal, misalnya rusaknya cargo block, putusnya wire. Karena kapasitas SWL crane di kapal hanya mampun mengangkat beban tidak lebih dari 30 ton".

Mualim I akan melakukan rencana untuk menangani muatan tersebut agar dapat diangkat tanpa merusak crane. Di sini peran Mualim I sebagai perwira yang bertanggung jawab terhadap muatan sangat dibutuhkan. Berikut cara untuk menangani muatan SWL crane yang direncanakan oleh Mualim I:

a. Muatan diangkat dengan 2 crane

SWL crane di kapal MV. Oriental Jade hanya 30 ton. Sedangkan beban yang diangkat berkisar 35 ton. Dengan cara menggabungkan 2 crane untuk mengangkat muatan tersebut beban yang ditanggung oleh masing-masing crane tidak terlalu berat sehingga muatan dapat diangkat dengan 2 crane yang diangkat bersama-sama.

Pengangkatan dengan menggunakan crane sangat beresiko tinggi jika tidak diperhitungkan dengan baik dan dilakukan sesuai prosedur. Berikut adalah cara pengangkatan muatan dengan 2 crane :

1) Hanya personil yang berwenang memegang SIO yang diperbolehkan mengoperasikan crane;

2) Crew yang melakukan pengikatan

(rigging/slinging) akan diberi pelatihan khusus;

3) Pemeriksaan harian terhadap crane dan alat bantu angkat harus 
dilakukan sebelum pengoperasian;

4) Semua sling, tali kawat baja dan lain-lain harus ditangani, dilumasi dan disimpan dengan benar untuk mencegah terpelintir, karat, dan putusnya kawat dapat menimbulkan bahaya bagi crew. Penanganan sling harus diperhatikan dengan serius agar dapat menunjang pelaksanaan bongkar muat yang efektif;

5) Pengalas yang sesuai harus digunakan untuk mencegah kerusakan pada sling, rantai dan sebagainya, pada saat bergesekan dengan permukaan atau ujung yang tajam;

6) Pengait dan shackle harus dilengkapi dengan pengaman yang efektif untuk memastikan beban tidak terjatuh dengan tibatiba;

7) Pakailah sarung tangan ketika memegang tali kawat;

8) Ketahui beban kerja aman yang tertera pada alat takel atau tali-temali yang digunakan. Jangan sampai melebihi batas maksimum;

9) Hitung total berat beban sebelum diikat;

10) Periksalah semua perangkat keras, peralatan, alat tackel dan sling sebelum digunakan dan laporkan peralatan yang rusak kepada Supervisor;

11) Dilarang menunggangi alat pengangkut, muatan, atau setiap permukaan bulat di crane dan alat derek lainnya;
12) Jangan memanjat atau menuruni peralatan yang sedang bergerak. Jangan meloncat dari peralatan apapun. Gunakan kedua tangan saat naik atau turun dari suatu peralatan;

13) Hindari tangan anda dari titik jepit saat mengait, menyambung atau menjepit;

14) Tali pengaman (tag line) harus digunakan untuk pengangkatan beban yang panjang;

15) Semua kait harus dililit, kecuali bila sudah dilengkapi dengan palang pengaman;

16) Hanya satu orang, yang harus diketahui operator, yang boleh memberikan kode atau isyarat kepada operator;

17) Operator crane harus diberi pengarahan oleh supervisor mereka sebagai bagian dari job safety analysis;

18) Pertimbangan terhadap faktor-faktor keselamatan kerja harus dievaluasi ulang jika sudut sling melebihi $60^{\circ}$;

19) Karena pertimbangan akan berat dan pusat gaya berat, maka semua muatan harus dicek sebelum diangkat. Pastikan peralatan pengangkatan sesuai dengan kapasitasnya;

20) Gunakan sling berkaki banyak, bukan gabungan sling dari kaki tunggal. Jangan mengangkat beban memakai satu dari sling kaki banyak sebelum kaki- 
Vega F. Andromeda ${ }^{a}$ dan Danang Wahyu Pratama ${ }^{b}$

kaki yang tidak terpakai diikat dengan aman;

21) Rapat pra-pengangkatan (Pre-lift meeting); Membahas penentuan tugas dan peran semua pihak, macam cara pengangkatan, tingkatan personil yang terlibat.

22) Persiapan pengangkatan (Lift Preparation). Inspeksi crane/mesin pengangkat, peralatan, shackle dan sling, melaporkan komponen untuk perbaikan, pengujian fungsi operasi crane, identifikasi ukuran sling yang tepat dan shackle untuk pengangkatan beban;

23) Komunikasi dengan personil di lingkungan kerja (dilakukan secara lisan dan melalui radio);

24) Sinyal (isyarat) penggunaan radio dan atau aba-aba tangan/hand signal yang ditunjuk;

25) Gerakan putaran (swing) crane tidak boleh menswing beban, menjaga titik pusat tegak lurus dengan hook pada boom;

26) Pengangkatan khusus (Non-routine operation); Kehati-hatian terhadap kerja aman, untuk heavy lifting cargo, pandangan operator yang terhalang, kapal yang beroperasi disekitarnya, bongkar muat dari bagian kapal, penangan cargo tanpa tag line, Pandangan yang terbatas, cuaca buruk/gelombang besar harus diperhatikan agar tidak terjadi kesalahan ketika proses pengangkatan dilaksanakan;

27) Laksanakan pengangkatan muatan dengan hati-hati dan sesuai aba-aba tangan dari signalman yang ditunjuk.

b. Muatan diangkat dengan HMC (Harbour Mobile Crane)

HMC (Harbour Mobile Crane) merupakan fasilitas bongkar muat yang disediakan oleh pelabuhan, ketika menjumpai muatan yang melebihi SWL crane, maka HMC (Harbour Mobile Crane) dapat digunakan sebagai pilihan kedua jika dengan menggunakan 2 crane tidak mampu mengatasi. HMC (Harbour Mobile Crane) mempunyai kapasitas SWL beragam sesuai tipenya. Kapasitas SWL antara 40 ton hingga 100 ton. Sangat efektif untuk mengangkat beban yang tidak mampu diangkat oleh crane kapal.

Dalam pengoperasiannya, HMC (Harbour Mobile Crane) tidak terlalu rumit dan membutuhkan banyak orang seperti menggunakan crane kapal. Lebih ringkas dan mudah menggunakan HMC (Harbour Mobile Crane). Crew kapal tidak terlibat dalam penggunaan HMC (Harbour Mobile Crane) karena telah ditangani oleh pihak darat, mulai dari persiapan hingga proses pengangkatan muatan sampai berada di atas kapal dengan selamat.

Dengan kapasitas SWL yang besar, HMC (Harbour Mobile 
Crane) dapat dengan mudah mengangkat beban yang melebihi kapasitas SWL crane. Pelaksanaan pengangkatannya pun tidak terlalu membutuhkan banyak orang, berikut adalah cara pengangkatan dengan HMC (Harbour Mobile Crane):

1) Pasang lifting equipment yaitu spreader bar beserta chainsling yang sudah terpasang pada cargo block HMC (Harbour Mobile Crane).

2) Pasang chainsling pada muatan yang akan diangkat, pastikan semua terpasang dengan benar.

3) Jika sudah terpasang dengan benar, beban diangkat pelanpelan dengan memerhatikan keadaan sekitar.

4) Ketika muatan sudah berada di atas deck, lepaskan chainsling yang terpasang pada muatan.

\section{PENUTUP}

\section{Simpulan}

Simpulan yang dapat diambil dari penelitian tentang pelaksanaan bongkar muat dengan menggunakan crane kapal di MV. Oriental Jade adalah :

1. Pelaksanaan bongkar muat dengan menggunakan crane kapal di MV. Oriental Jade :

a) Dengan adanya persiapan yang baik sebelum bongkar muat dengan menggunakan crane menentukan lancar dan tidaknya pelaksanaan bongkar muat.

b) Kegiatan bongkar muat dengan menggunakan crane dapat berjalan lancar karena sesuai dengan prosedur.
2. Jika muatan yang melebihi SWL crane:

a) Muatan yang melebihi SWL crane dan di darat tidak tersedia CC (Container Crane) maupun HMC (Harbour Mobile Crane) maka dapat diatasi oleh crew kapal dengan alternatif menggunakan dua crane yang digunakan bersama-sama atau digabungkan untuk mengangkat muatan tersebut serta bagaimana cara menanganinya.

b) Menggunakan HMC (Harbour Mobile Crane) lebih kecil resiko kegagalan dalam mengangkat beban muatan yang melebihi SWL crane kapal, karena HMC (Harbour Mobile Crane) menpunyai SWL yang lebih besar.

\section{Saran}

Berdasarkan hasil pembahasan di atas mengenai pelaksanaan bongkar muat dengan menggunakan crane kapal, maka penulis memberi saran sebagai berikut.

1. Pelaksanaan bongkar muat dengan menggunakan crane kapal di MV. Oriental Jade :

a) Sebelum persiapan bongkar muat dengan menggunakan crane kapal sebaiknya diadakannya meeting untuk memberikan pengarahan terhadap crew tentang prosedur yang baik dan benar, sehingga diharapkan dapat terlaksana kerjasama yang baik.

b) Kegiatan bongkar muat yang dapat berjalan dengan lancar sebaiknya didukung oleh pihak kapal dan pihak darat. Serta penyediaan alat bongkar muat yang baik dan siap digunakan.

2. Jika muatan melebihi SWL crane :

a) Menggunakan 2 crane untuk mengangkat muatan yang melebihi SWL crane sangat tinggi resikonya, lebih baik dilakukan 
Vega F. Andromeda ${ }^{a}$ dan Danang Wahyu Pratama ${ }^{b}$

rapat pra-pengangkatan (Pre-lift meeting). Membahas penentuan tugas dan peran semua pihak, macam cara pengangkatan, tingkatan personel yang terlibat.

b) Jika di darat terdapat HMC (Harbour Mobile Crane) lebih baik menggunakan HMC (Harbour Mobile Crane) daripada menggunakan crane kapal, karena HMC (Harbour Mobile Crane) menpunyai SWL yang lebih besar daripada crane kapal dan agar lebih aman guna memperkecil kecelakaan kerja dan melindungi crew kapal dan muatan.

\section{DAFTAR PUSTAKA}

Komarudin. 2004. Ensiklopedia Manajemen. Bandung: Penerbit Almuni

Martopo, Arso dan Soegiyanto. 2004. Penanganan dan Pengaturan Muatan. Semarang: Politeknik Ilmu Pelayaran Semarang

Moleong, Lexy J. 2002. Metodologi Penelitian Kualitatif. Bandung: Remaja Rosdakarya . 2006. Metodologi Penelitian Kualitatif. Bandung: Remaja Rosdakarya

Sukardi. 2003. Metode Penelitian Pendidikan. Jakarta: Bumi Aksara

Nazir. 2005. Metode Penelitian. Bogor: Ghalia Indonesia

Nawawi, Hadari. 2004. Metode Penelitian Bidang Sosial. Yogyakarta: Universitas Gajah Mada
Salim, Abbas. 2004. Manajemen Transportasi. Jakarta: Raja Gravindo Perkasa

Sarwono, Jonathan. 2006. Metode Penelitian Kualitatif dan Kuantitatif. Yogyakarta: Graha Ilmu

Supardi. 2003. Kerangka Dasar dan Paradigma Penelitian. Semarang: Universitas Negeri Semarang

Suwiyadi, HR. M. Transportasi Laut dan Bisnis Pelayaran. Semarang: Politeknik Ilmu Pelayaran Semarang 